\title{
The Role of Community Based Health Insurance Scheme on Financial Protection and Healthcare Seeking Behavior of Households in Tehuledere District, Northeast Ethiopia
}

\author{
Molla Yismaw Jembere \\ Department of Sociology, Wollo University, Desssie, Ethiopia \\ Email address: \\ mollayismaw1@gmail.com \\ To cite this article: \\ Molla Yismaw Jembere. The Role of Community Based Health Insurance Scheme on Financial Protection and Healthcare Seeking Behavior \\ of Households in Tehuledere District, Northeast Ethiopia. International Journal of Health Economics and Policy. \\ Vol. 3, No. 2, 2018, pp. 13-19. doi: 10.11648/j.hep.20180302.11
}

Received: June 9, 2018; Accepted: July 4, 2018; Published: July 30, 2018

\begin{abstract}
Healthcare financing in many developing countries dominantly come from out-of-pocket expenditure, and it has remained problematic for its catastrophic consequences on the poor. Community based health insurance scheme become potential strategy to protect households from out- of -pocket expenditure and impoverishment, and access affordable and effective healthcare. Therefore, this study examined the role of community based health insurance on financial protection and healthcare seeking behavior of households in rural Ethiopia. Mixed research approach employed concurrently to collect data from participants, and collected data were analyzed through descriptive, inferential and thematic analysis. The study finding revealed that $71.5 \%$ of households protected from extra out of payments (other than premium payment for the scheme). Furthermore, large number of respondents (66.3\%) replied that price for the scheme was easily affordable. Moreover, by avoiding out -of -pocket payment, community based health insurance improve healthcare seek behavior of households from modern healthcare providers. However, there were challenges in reimbursement, moral hazards or miss utilizations and adverse selections or the inclusion of chronically ill, poor and fee waivers during enrolment. In general, in the absence of third party and prepayment systems such as health insurance and tax-based healthcare financing, households in many low-income countries are exposed to the financial risks of paying large medical bills from out-of-pocket demands introduction of community based health insurance as alternative financial approach.
\end{abstract}

Keywords: Community Based Health Insurance Scheme, Financial Protection, Mixed Research Approach, Healthcare Seeking Behavior, Ethiopia

\section{Introduction}

Healthcare financing in many developing countries dominantly come from out-of-pocket expenditure which impose catastrophic consequences on the poor; pave the way to the establishment of alternative healthcare financing approach such as health insurance scheme [1].

In many developing countries, millions of people so far suffer because they cannot access affordable health care services or for the reason that paying for health care results in severe financial hardship or pushes them into deep poverty [2]. A study by World Health Organization [3] stated that globally, about 150 million people face catastrophic health expenditures every year and 100 million fall into poverty after paying for healthcare.

In Africa, population still depend on mostly on out-ofpocket payments (accounting for 30\%-85\% of total health spending in the poorest countries, and $37 \%$ in Ethiopia), which are associated with incurring very costly health expenditure. As a result, healthcare seeking behavior, services utilization and quality of service in Ethiopian remain very low $[1,4,5]$.

Ethiopian healthcare system was largely reliant on out of pocket spending, exposing many households to financial hardship and causing them to give up seeking healthcare especially in rural Ethiopia. Poor health care financing in Ethiopia slowdown health improvements on access, quality and utilization of essential health services among the poor 
and rural communities [4, 6]. For example in 1999/2000 the government and other public enterprises provide $31 \%$ of the financing, donors and Non-Government Organizations provide $37 \%$, households provide $31 \%$ and other private employers and fund about $1 \%$ [7, 8]. Out of pocket expenditures of households increased from 31\% in 1999/2000 to $37 \%$ in 2010 due to high reliance on out of pocket expenditure and low government spending on the health sector [4].

Community based health insurance scheme (CBHI) introduced in responses to high out of pocket expenditure, low services utilization and poor quality of services; in 2011, the government of Ethiopia introduced two types of health insurance schemes. The first is community based health insurance scheme (CBHI) for rural households and people engaged in the informal sectors intended to cover majority $(83.6 \%)$ of the population and the second is social health insurance which is mandatory health insurance program for formal sector. Accordingly, the pilot CBHI scheme was introduced in 13 Districts located in four regions (Tigray, Amhara, Oromiya, and SNNPR) of Ethiopia [4].

Different studies have been conducted regarding the role of $\mathrm{CBHI}$ on financial protection and healthcare seeking behavior of households. For example, the principal advantages of using CBHI over out of pocket payment is that the use of the CBHI scheme separates time of payment for health care from the time of use of services, which is better suited to rural households due to their seasonal disparities of income and expenditures. Because, poor people lack the resources to pay for health care; they are less likely than the rich people to seek healthcare [9].

Furthermore, in Ethiopian, the impact of CBHI in the whole country found out that 45 to 64 percent increase in the frequency of visits to public providers $[10,11]$. Moreover, socio-cultural barriers such as, income, age and sex were factors affecting healthcare seeking behavior from modern healthcare providers $[12,13]$.

Even through, health insurances has emerged both as way of augmenting financial recourses available for healthcare, and means of provision of services especially in developing countries [14], in Africa, health insurance is relatively limited to few countries. Yet, community-based health insurance is practiced in few countries like Ghana, Rwanda, Senegal, Nigeria, Tanzania, South Africa, and Burkina Faso $[15,16]$. Despite the existence of studies on $\mathrm{CBHI}$ and its role on financial protection and healthcare seeking behavior, previously studies focused on healthcare behavior in Ethiopian context, most focus on access and use of services in specific geographic community were not linked with the introduction of CBHI scheme. Therefore, this study examined the role of community based health insurance on financial protection and healthcare seeking behavior of households in rural Ethiopia following the introduction of community based health insurances scheme particularly on Tehuledere District in South Wollo Zone, northeast Ethiopia.

\section{Methods}

\subsection{Study Setting}

This study was conducted in Tehuledere District in South Wollo Zone, Amhara Regional State in northeast Ethiopia located 430 kilometers from Addis Ababa on the main road to Woldiya and Mekelle. The District has total population of 110,226 among this, $59,238(53.74 \%)$ are males and the remaining $50.988(46.26 \%)$ are females. Majority of the population 107, $055(97.12 \%)$ are rural population and only $3,171(2.88 \%)$ are urban population [17].

Following the introduction of new health insurance strategy in 2010/11 in Ethiopia, the District was one of 13 pilot Districts where the community based health insurances schemes instigated at the national level. The average enrollment rate for Tehuledere District was 91\% which is significantly higher acceptances rate of CBHI than the national average $(52.4 \%)$ of the eligible households' nationally [16]. Tehuledere District has 26 health posts and five public health centers, six small private clinics and three medium private clinics that provide healthcare serves [18].

\subsection{Study Design}

Cross-sectional study design employed to gather factual data from $344 \mathrm{CBHI}$ member head of household respondents and purposively selected informants. Informants were selected from health professionals, CBHI scheme workers, community leaders and government officials. Relevant retrospective data on financial difficulties for healthcare access, healthcare seeking behavior for an illness episodes occurred in the past was also generated from March $4^{\text {th }}$ to April $7^{\text {th }}, 2017$ Mixed research approach was employed to collect data through qualitative and quantitative approaches in order to reconcile between the limitations with the representativeness from qualitative approach and reductionist nature of the quantitative approach. Household survey, Focus Group Discussions (FGDs), key informant and in-depth interviews were carried out to collect primary data.

\subsection{Study Population and Sampling}

\subsubsection{Study Population}

Study participants were selected from rural households, CBHI scheme workers, healthcare professionals, kebele administrative, religious leaders and elderly of the community. The study participants were recruited by employing both probability (for survey) and non-probability (for qualitative) sampling designs. Tehuledere District has 21 rural Kebeles /tabias (the lowest administrative unit in Ethiopia.

\subsubsection{Sample Size and Sampling}

Tehuledere District 21 rural Kebeles were the primary sampling units of the study. The District Kebeles were stratified in to three agro-ecological zones (Dega, Woina dega and Kola) assuming varied distribution of diseases, illness episode, health risk factors, healthcare seeking 
behavior, psycho-social and economic characteristics, and ways of life in these agro-ecological zones. Lottery method was used to select one sample kebele from each agroecological zone. Then, 344 respondents were selected from thee total of 2471 insured households using simplified proportion sample size estimation formula;

$$
\mathrm{n}=\mathrm{N} /(1+\mathrm{N}(\mathrm{e}) 2)
$$

provided by Yamane [19] to determine the required sample size at a confidence level of $95 \%$, and a 0.05 margin of error. Where; $\mathrm{n}$ is the sample size to be selected, e- is the acceptable sampling error, N-the population size and $95 \%$ confidence level, and $\mathrm{p}=0.5$ were assumed.

Households for the survey were selected by employing systematic sampling technique based on the updated sampling frame acquired from District CBHI office. Finally, at household level either the head of the household or spouses of the head of the households were randomly selected for the study. The informants of qualitative research were recruited by using purposive sampling technique. Thus, six in-depth-interviews with patients who come frequently to healthcare facilities were interviewed. Moreover, key informant interview had been made with three health extension workers; who give services for selected Kebeles, three kebele leaders; from each Kebele, one CBHI scheme worker; District CBHI scheme coordinator; seven health care professionals; who have long experiences were interviewed. In addition, three FGDs had been made with households.

\subsection{Data Collection Procedures}

Semi-structured and pretested questionnaire was used and full-scale data gathering exercise was carried out by researcher and data collectors. Qualitative data were collected concurrently with the quantitative data. Data from key informant interview and in-depth interview were collected by the researcher, and data from Focus Group Discussions (FGDs) were collected by the researcher with trained facilitator. Training and appropriate supervision of data collectors were employed to control data quality.

\subsection{Data Processing and Analysis}

The questionnaires completed by respondents were checked for completeness and consistency, then coded, and entered into SPSS version 20 statistical software for final analysis. Descriptive statistics such as text, table, frequency, and percentage used to describe socio-demographic characteristics and health care seeking behavior of respondents. Statistical tests and models of such as, T-Test and one way ANOVA were employed to examine group differences and Pearson correlation used to see the relationships. Each outcome variable was then investigated and 95\% confidence interval was assumed. Results were considered significant at the $\mathrm{p}<=$ 0.05 significant level. The qualitative data were summarized and presented concurrently alongside with the quantitative data by using thematic analysis technique.

Subsequently, based on the similarity of the themes, qualitative data were integrated with the quantitative ones concurrently based on themes in sequences of the study objectives.

\subsection{Ethical Considerations}

The study was approved by Ethical clearance obtained from Addis Ababa University together with a permission letter approved by Addis Ababa University department of sociology. Later, Thehuledere District administrative office, and all selected study kebeles were communicated with formal letter. Each study participant was briefed on the study objective and verbal consent was granted and confidentiality was assured for any information provided.

\section{Results}

\subsection{Socio-Demographic Characteristics of Respondents}

A total of $344 \mathrm{CBHI}$ member households were included in the study for household survey. According to the data obtained from the survey, socio-demographically, most respondents were male $(77 \%)$, majority $(46 \%)$ respondents were with age group of 36-50, and significant majority (94.25\%) belongs to the same religious category (Muslim), among the respondents, most of them (87.5\%) are married. Regarding family size, half of respondents do have family size of 4-5 members and more than half respondents can't read and write. Moreover, nearly half $(46.2 \%)$ belongs to low income category.

\subsection{The Role of CBHI Scheme on Financial Protection}

Health costs, if paid by selling assets, not only have the potential to reduce current assets, but also reduce farm productivity, nutrition intake, and future stream of income. To avoid these costs, households tend to delay or forgone appropriate treatment, exposing them to greater health risks. However, recently, the role of CBHI in improving access to the formal healthcare services in low and middle income countries including Ethiopia has been significant by providing financial security from the cost of seeking healthcare services, involves prepayment for health services by community members. For example table below shows majority $(76.5 \%)$, member households paid 240 ETB (nearly $\$ 8.72$ USD based on current exchange value) premium payment for one year for family members less than six, $12.7 \%$ and $10.8 \%$ of the respondents paid 336 and above, and 288 ETB for 2009/10 E. C. premium payment respectively. Those households who have more than five family members should pay additional 48 ETB (nearly $\$ 1.75$ USD based on current exchange value) for each extra individual family member.

Furthermore, households were asked about level of payment for CBHI scheme; consequently, fairly large number of respondents $(44.5 \%)$ replied that price is moderate followed by $21.8 \%$ very cheap. Among the respondents, $19.8 \%$ responded that price is cheap. However, small portion of households, $11.6 \%$ and $2.3 \%$ replied that the payment for $\mathrm{CBHI}$ scheme was expensive and very expensive. 
Table 1. Premium payment to Community based health insurance.

\begin{tabular}{llll}
\hline Item & Reponses & Frequency & Percentage (\%) \\
\hline & 240 & 263 & 76.5 \\
Amount of Money Paid for 2009/10 E. C. & 288 & 37 & 10.8 \\
& 336 and above & 44 & 12.7 \\
& Total & 344 & 21.8 \\
& Very Cheap & 75 & 19.8 \\
Premium and membership & Cheap & 68 & 44.5 \\
Payment Level of CBHI Scheme & Moderate & 153 & 11.6 \\
& Expensive & 40 & 2.3 \\
& Very Expensive & 8 & 100.0 \\
& Total & 344 & 71.5 \\
Amount of Extra Payment for Healthcare for the Last Three & No Extra Payment & 246 & 6.4 \\
Months in ETB (Ethiopian Birr) & 100 and Less & 22 & 8.4 \\
& $100-200$ & 29 & 4.1 \\
& $201-400$ & 14 & 9.6 \\
\hline
\end{tabular}

Source: Sample Survey, 2017; n=344

Moreover, regarding extra payment (other than premium payment) they expense for health care in the last three months, majority $(71.5 \%)$ were not charged extra payment. However, $9.6 \%$ of households were exposed for additional payment of more than $400 \mathrm{ETB}$ for the last three months followed by $8.4 \%$ who expensed $100-200$ user fee payment. Of the total respondents, $6.4 \%$ and $4.1 \%$ paid extra out of pocket payment of less than 100 and 201-400 ETB correspondingly. The above claim also supported by most informants. For example, one of the informants stated the relative advantage of CBHI scheme compared to out of pocket payment in relation to price as follows:

"I paid 240 ETB for one year. If I go to private health facility for example, hospital 240 birr is used only for two times card payment; there are private hospitals in Dessie that cost 120 birr for card only. So, the price of CBHI scheme is very cheap. Know a day's 240 ETB is a price of one hen; we can use one year service for all family members by selling one hen. I do have a friend who is not member of the CBHI scheme, in August, 2008 E. C. his wife were very sick and referred to hospital and she admitted to a week in hospital. He told me that he sold a cow to afford the price and this year he becomes member to the scheme (women, 41 -year old- in- depth interviewee).

Another in-depth interview informant supports the above statement and narrated her experience about the price of CBHI scheme as:

Community based health insurance is very cheap, and I believe everyone can afford the premium payment and get better advantage from it. For example, I was very sick three months ago but the service was not available at public healthcare facilities. I got referral for private hospital and got treatment with out of pocket payment. I was admitted for inpatient services for three days. After three days somehow I got relief but they cost me 4800 birr which was very expensive to afford and above my ability to manage to pay. However, thanks to CBHI scheme, the payment I paid reimbursed to me, that means I got a bonus of 4560 ETB by paying 240 ETB premium payment (woman in- depth interviewee, age-44).

However, according to the survey, yet, considerably large numbers of respondent households were exposed for additional healthcare payment in the last three months even if they are member to CBHI scheme. Paying out of pocket is a problem for members who have already paid premium for CBHI scheme may not have household budget left for these contracted services. In addition to the survey one informant stated premium for the scheme and increments of payment over the year as, unplanned and did not consider their (households) conditions through his statement:

Payment to CBHI scheme increases year to year, it was 36 ETB first then 180 ETB and now we have to pay 240 ETB even if we did not use any service. This is not the only problem; we forced to pay with other payments. The payment should request twice a year independent of other payment so that we can afford it easily (in-depth interviewee man, age- 39).

In general, data from household survey, and informants showed that CBHI scheme for most households is affordable and CBHI protected households from high out of pocket payments, and most households received services according to the scheme agreements.

\subsection{Occurrences of Illness and Healthcare Seeking Behavior of Households}

\subsubsection{Occurrences of Illness and Treatment Choice}

The process of seeking healthcare services start with occurrences of illness or injuries followed by immediate responses and choice of treatments. Most of the respondents and all informants replied that there were occurrences of illness within in the family member for the last three months. Before the introduction of $\mathrm{CBHI}$ scheme, most of the respondents and informants replied that they visited modern health care institutions and half of the respondents considered traditional healers as a means to remedy. However, after the introduction of CBHI scheme choice of modern healthcare facilities increase, on the other hand, seeking treatment from traditional healers and using home remedies for illness and injuries decline. 


\subsubsection{The Role of CBHI Scheme on Healthcare Seeking Behavior}

According to data obtained from respondents and informants CBHI scheme promote healthcare seeking behavior of rural households especially, for excluded people particularly, for the poor and chronically ill; hence, poor can benefitted by indigents entitlement and the chronically ill can be cross -subsidized by the healthy. Hence, by avoiding out of pocket payment $\mathrm{CBHI}$ scheme become instrument to achieve universal health coverage. For example figure 1: shows that even although overall healthcare seeking behavior increase, utilization of services varies across different segment of society.

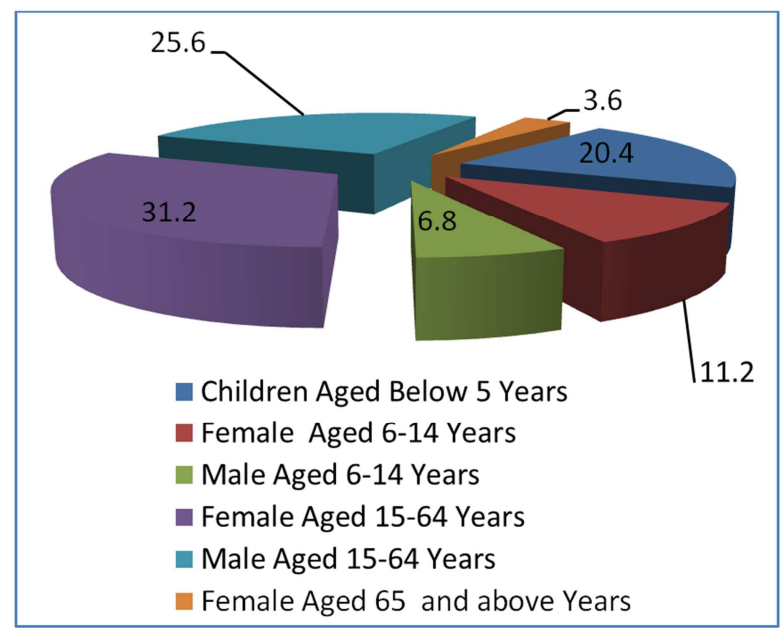

Source: Sample Survey, 2017; n=344

Figure 1. The role of community based health insurance in healthcare seeking behavior and services utilization.
The above Figure depicted the percentage of illness occurrences and service utilizations in terms of sex and age for the last three months indicate that, female aged 15-64 years $(31.2 \%)$ visited health services more frequently followed by male aged 15-64 years, and children aged below 5 years $(20.4 \%)$ put in third place. Among the respondents, female aged 6-14 years accounts $11.2 \%$, and male aged 6-14 years constitutes $6.8 \%$, the remaining $3.6 \%$ and $1.2 \%$ covered by female and male aged 65 and above years respectively.

\subsubsection{Predisposing Factors (Socio - Demographic Characteristics) and Healthcare Seeking Behavior}

Using socio- behavioral model of Anderson and Newman, the finding of the study discloses test statistics infers predisposing characteristics such as, sex and household size were statistically significant; and shows group differences on the aforementioned variables in services utilization and healthcare seeking behavior in the last three months.

Additionally, positive relationship between age and household size to health services utilization is notice. Unlikely, differences in religious affiliation was not significant, and there was no difference in services utilization and healthcare seeking behavior between those group categories.

In additions, from the enabling factors being membership to CBHI scheme tested through was statistically significant at $\alpha=$ 0.01 . However, the test statistics is not statistically significant at $\alpha=0.05$ for groups who have different level of income. Hence, the prime role of CBHI scheme is to cross-subsidize households and reduce financial barriers so that every member can use health services equally when services demanded.

Table 2. Socio-demographic (predisposing) and enabling characteristics and health service utilization of Respondents

\begin{tabular}{|c|c|c|c|c|}
\hline \multicolumn{3}{|c|}{ Predisposing factors and enabling (Factors) } & \multicolumn{2}{|c|}{ Health seeking behavior / visits of health facilities } \\
\hline \multicolumn{5}{|l|}{ Predisposing factors } \\
\hline \multicolumn{2}{|l|}{ Characteristics and Variables } & Frequency and Percentage & Test statistics & Sig. at $\mathrm{p}<=005^{*}$ \\
\hline \multirow{2}{*}{ Sex } & Male & $265(77.0 \%)$ & \multirow{2}{*}{ T-Test } & \multirow{2}{*}{0.001} \\
\hline & Female & $79(23.0 \%)$ & & \\
\hline \multirow{4}{*}{ Age } & $18-35$ & $57(16.6 \%)$ & \multirow{4}{*}{ Pearson Correlation } & \multirow{4}{*}{$0.002 * *$} \\
\hline & $36-50$ & $151(43.9 \%)$ & & \\
\hline & $51-64$ & $70(20.3 \%)$ & & \\
\hline & 65 and Above & $66(19.2 \%)$ & & \\
\hline \multirow{3}{*}{ Religious Afflation } & Orthodox & $19(5.5 \%)$ & \multirow{3}{*}{ One way ANOVA } & \multirow{3}{*}{$0.586^{*}$} \\
\hline & Muslim & $324(94.2 \%)$ & & \\
\hline & Catholic & $1(.3 \%)$ & & \\
\hline \multirow{4}{*}{ Household Size } & $1-3$ & $38(11.1 \%)$ & \multirow{4}{*}{ Pearson Correlation } & \multirow{4}{*}{$0.001 * *$} \\
\hline & $4-5$ & $169(49.1 \%)$ & & \\
\hline & $6-7$ & $106(30.8 \%)$ & & \\
\hline & Above7 & $31(9.0 \%)$ & & \\
\hline \multicolumn{5}{|l|}{ Enabling factors } \\
\hline \multirow{3}{*}{ Income level (enabling variables) } & High & $50(4.5 \%)$ & \multirow{3}{*}{$\begin{array}{l}\text { One way ANOVA } \\
\text { (F-Test) }\end{array}$} & \multirow{3}{*}{0.382} \\
\hline & Middle & $135(39.3 \%)$ & & \\
\hline & Low & $159(46.2 \%)$ & & \\
\hline \multirow{2}{*}{ membership to $\mathrm{CBHI}$} & Yes & $313(91.0 \%)$ & \multirow{2}{*}{ T-Test } & \multirow{2}{*}{0.000} \\
\hline & No & $31(9.0 \%)$ & & \\
\hline
\end{tabular}

*=significant (sig.) at $\mathrm{p}<=0.005$ or at $\mathrm{p}<=0.001$

Source: Sample Survey, 2017; $\mathrm{n}=344$ 


\section{Discussions}

Developing countries like Ethiopia have made little progress to cover people in the informal sector and rural population and out of pocket healthcare expenditure remain main cause of low healthcare utilization, low quality of services and high out-of-pocket payment result impoverishments of households. Poor health care financing remains a major challenge for the health system of Ethiopia. It leaves households vulnerable to impoverishment from catastrophic health expenditures, and slows progress towards health improvements such as the Universal Health Coverage by limiting access to essential health services among the poor $[4,20]$.

Similar to other empirical studies, the finding of this study showed that before the introduction of CBHI scheme, by triggering high economic costs for health care services, households were severely threaten by high out of pocket payments and patients were vulnerable for prolonged chronic illness that come from delay to seek treatment. Despite this great risk in many often neither the government nor the market offers appropriate and affordable health insurances for poor households.

However, after the introduction of CBHI scheme, results suggested reduction in out of pocket expenditures; of the total sampled households $71.5 \%$ of households protected from extra out of payments (other than premium payment for the scheme). However, due to problem of reimbursement and lack of awareness about the procedure in services utilization through community based health insurances channel, considerably large numbers of respondent (28.5\%) households were exposed for additional healthcare payment (ranging from one to more than four hundred birr) in the last three months even if they are member to CBHI scheme; which may result dropouts from the scheme. However, this study indicated that $86.1 \%$ of respondents considered the payment level with in very cheap and moderate categories; they prefer payment of the scheme over out of pocket payments.

Correspondingly, the finding of this study similar to other studies; for example, a study conducted in developing countries particularly in Sub Sahara-Africa showed that CBHI schemes can be effective for reaching a large number of poor and near poor people who would otherwise have no financial protection against the cost of illness especially, in countries where national insurance schemes do not exist and/or where public health care funding is insufficient [21].

Furthermore, evidence from rural Senegal disclosed that public funding to subsidize premiums for the poor; promoting increased revenue collection from the "healthy and wealthy" so as to enhance cross-subsidization and risk pooling; improved CBHI management; and improved purchasing to enhance quality of care and health seeking behavior of households [22]. Additionally, empirical evidence from Rural Tanzania showed that nearly 55\% of non-member households relied on their own savings to finance their drug expenses compared to less than $11 \%$ for member households. More than 20\% of non-member households were obliged to cover the health expenses for sick individuals by selling crops, while this downs to less than $10 \%$ for member households [23].

Correspondingly, this study discloses that the existence of high out-of-pocket expenditure on health care is an indication of capacity and willingness of households to pay for healthcare service, which is a necessary requirement for the establishment of health insurance.

\section{Conclusion and Recommendation}

In the absence of third party and prepayment systems such as health insurance and tax-based healthcare financing, households in many low-income countries including Ethiopia are exposed to the financial risks of paying large medical cost from out-of-pocket. Recently, community based health insurance as a new approach has been regarded as a promising solution to this healthcare financial strategy for rural households.

Based on this finding, affordability and get rid of out of pocket payment for health service is important to improve households' healthcare seeking behavior. Furthermore, the premise of healthcare financing therefore does not only involve how to raise sufficient resources to finance health care needs of countries, but also on how to ensure affordability and accessibility of healthcare services, equity in access to medical services as well as guarantee financial risk protection of households.

Like other, empirical researches the finding of this study discloses that community based health insurance has turned out to be a useful financial tool in the health sector reform in Ethiopia in general and in the study area in particular. Hence, the out of pocket for health care services have had very limited impact because it failed to cover informal sector poor workers and the rural self-employed, who constitute the majority of the countries populations, CBHI scheme turnout to be realistic option to access health care for all, and to meet universal health coverage (UHC).

However, improving affordability is a necessary condition, but careful consideration should be given to other dimensions of design and complementary interventions during implementations of basic parameters of the scheme. Thus, both members and providers need strong policy framework implementation in national, regional and District level. Awareness about services utilization, benefit package, services provision and community mobilizations for risk pooling and additional revenue collection, alternative finance generating mechanisms needed inter and intra sectorial linkage for the sustainability of the scheme.

\section{Acknowledgements}

The researcher would like to thank Addis Ababa University for its financial support to the realization of the 
study which this article is extracted. The researcher would also like to thank the study participants and data collectors who participated in this study.

\section{Nomenclature}

$\begin{array}{ll}\text { ANOVA } & \text { Analysis of Variance } \\ \text { CBHI } & \text { Community Based Health Insurance } \\ \text { ETB } & \text { Ethiopian Birr } \\ \text { FGD } & \text { Focus Group Discussions } \\ \text { FMoH } & \text { Federal Ministry of Health } \\ \text { MOFED } & \text { Ministry of Finance and Economic Development } \\ \text { SNNPR } & \text { South Nations Nationalities and People } \\ \text { USD } & \text { United States Dollar } \\ \text { WHO } & \text { World Health Organization }\end{array}$

\section{References}

[1] Jacobs, B., Maryam B., Maurits, P., Por, I., Cedric, S. and Bart C. Bridging community-based health insurance and social protection for health care - a step in the direction of universal coverage?. Tropical Medicine and International Health. Belgium. Blackwell Publishing Ltd; vol. 13 (2), 2008, pp. $140-143$.

[2] Wolfe, R., McIntyre, D., Honda, A. and Hanson, K. Covering the informal sector: Report from a workshop on expanding access to health services and financial protection for people outside the formal employment sector. 2014.

[3] World Health Organization (WHO). The world health report: health systems financing: the path to universal coverage. Geneva; 2010: pp. 15-50.

[4] Federal Ministry of Health Ethiopia (FMoH). Health Sector Development Programme IV: 2010/11 - 2014/15'. Addis Ababa: The Federal Ministry of Health; 2010.

[5] CSA (Central Statistical Agency (Ethiopia)). Ethiopia Demographic and Health Survey. Addis Ababa: Ethiopia; 2014.

[6] Anagaw Derseh. Essays on evaluating a community based health insurance scheme in rural Ethiopia. International institute of social studies. Nezerlands. Netherlands Organization for Scientific Research; 2015.

[7] FMoH. Health Sector Strategic Plan-III2005/06-2009/10. Addis Ababa: Planning and Programming Department, Ministry of Health. 2005.

[8] MOFED. Summary of Consolidated Federal and Regional Budget, 2008/09. Addis Ababa: MOFED. 2008.

[9] Liu. Y. and Hsiao, W.. For the People, by the People: Community Financing of Healthcare in Developing Countries. Harvard Health Policy Review. Vol. 4 (2), 2003, pp. 102-111.
[10] Anagaw Derseh. Mebratie, Robert Sparrow, Zelalem Yilma, Getnet Alemu Arjun S. Bedi. Enrollment in Ethiopia's Community-Based Health Insurance Scheme. World Development; 74, 2015, pp. 58-76.

[11] EHIA (Ethiopian Health Insurance Agency). Evaluation of Community-Based Health Insurance Pilot Schemes in Ethiopia: Final Report. Addis Ababa, Ethiopia; 2015.

[12] Dereje Wonde. and Getnet Tadele. Impedments of Health Seeking Behavior and Health Service Utilization from Healthcare Institutions in A Rural Community of Enebise Sar Mider Woreda, East Gojjam Zone, Ethiopia. Ethiop. J. Health. Dev. 29 (2), 2015, pp. 100-110.

[13] Fitsum Girma, Challi Jira and Belaineh Girma. Health Services Utilization and associated Factors in Jimma Zone, South West Ethiopia. Ethiop J Health Sci; vol. 21 (4): 2011, pp. 85-94.

[14] Hsiao, W. C. Unmet health needs of two billion: Is community financing a solution? HNP Discussion Paper. World Bank, Washington, DC. World Health Organization. Achieving universal health coverage: Developing the health financing system. Technical briefs for policy-makers, No (1), Geneva. 2001.

[15] WHO. Reporting on the Ethiopian World Health Survey 2003. Geneva: World Health Organization. 2005.

[16] USAID (United States of America International Development). Ethiopia Health Sector Financing Reform: Midterm Project Evaluation. Addis Ababa: The United States Agency for International Development; 2011.

[17] Tehuledere District Administration Document Office. General information about the study Area; 2017.

[18] Tehuledere District Community based health insurance Office Annual Report. Design and implementation of community based health insurance in the Study Area; 2016/17.

[19] Yamane, T.. Statistics: an introductory analysis. New York. Harper and Raw publication; 1967.

[20] WHO. Water, health and ecosystems. Available at: http://www. who.int/heli/risks/water/water/en/.2015.

[21] Wiesmann D. and Jutting, J. The Emerging Movement of Community Based Health Insurance in Sub-Saharan Africa: Experiences and Lessons Learned. Afrika spectrum vol. 35 (2) 2000.

[22] Jutting, J. P. 2003. Do community-based health care insurance schemes improve poor people's access to health care? Evidence from rural Senegal. World Dev. 32, 2003. pp. 273288.

[23] Msuya, J., Jutting, J. and Abay A. Impact of Community Health Funds on the Access to Health Care: Empirical Evidence from Rural Tanzania. International Journal of Public Administration, vol. 30 (8). 2007. 